www.jmscr.igmpublication.org

Impact Factor 5.244

Index Copernicus Value: 83.27

ISSN (e)-2347-176x ISSN (p) 2455-0450

crossref DOI:_https://dx.doi.org/10.18535/jmscr/v4i10.106

Journal Of Medical Science And Clinical Research

\title{
Effect of Probioites on the Time Taken to Reach Full Enteral Feeds in Preterm/ Very Low Birth Weight Infants
}

\author{
Authors \\ Sukanyaa $\mathbf{S}^{1}$, Ramesh $\mathbf{S}^{2}$, Vinoth $\mathbf{S}^{3}$ \\ ${ }^{1}$ Post Graduate, ${ }^{2}$ Professor \& HOD, ${ }^{3}$ Lecturer \\ Department of Paediatrics, Rajah Muthiah Medical College and Hospital, \\ Annamalai University, Chidambaram
}

\begin{abstract}
Probiotics are the most researched yet least used in neonatalogy in recent times. Probiotics are proposed to have a major role in promoting the feed tolerance in the preterm and very low birth babies.
\end{abstract}

\section{INTRODUCTION}

Probiotics were first described in literature as growth promoting factors produced by certain organisms. More recently, they are described as living organisms which when included in the diet in adequate amounts can bring health benefits to the host. They act upon the infant gut various mechanisms viz, competitively excluding the pathogens by inhibiting adhesion, competing for nutrients and receptors, strengthening the gut barrier by regenerating the epithielial cells, reinforcing tight junctions and restraining permeability of the pathogens, augmenting the secretory IgA production etc. Past researches all focussed on the reduction of NEC with the usage of probiotics whereas recent researches focus on the enteral nutrition. Generally selected strains of probiotics are similar to that present naturally in the gut under the assumption that these bacteria outnumber the resident bacteria in establishing a numerically significant level in the host. The most commonly used strains belong to the genera, Lactobacillus and Bifidobacterium. Furthermore, the use of multiple strains were beneficial in the time taken to reach full enteral feeds when compared with the use of monostrains. The effect was more pronounced when the diluent used was expressed breast milk.

\section{AIMS}

To observe the time for establishing full enteral feeds in the probiotic supplemented group in comparison with the non-supplementation group.

\section{METHODOLOGY}

Randomized controlled trial. Random numbers were generated and the babies were randomized into two groups-A \& B. Group (A) was taken as the control, who received only preterm care whereas Group (B) was supplemented with probiotics along with routine preterm care. Fig:1 Expressed breast milk was used as the diluent for the probiotics. It was administered through palladai twice daily at the introduction of the first feed. They were supplemented for upto one month of age. Time to reach Full enteral feeds was taken 
as the time taken for taking breast feeds directly. The results were tabulated and analysed.

\section{RESULTS}

Statistical analysis was done using the Independent $\mathrm{T}$ test and the results tabulated. 49 babies who met the inclusion criteria $(<1.5 \mathrm{kgs} /$ preterm $<34$ weeks of gestation) were taken into the study and placed into the two groups A \& B after randomization. 4 babies were excluded from the study as they were lost for follow up and were started on formula feeds during the study period. Analysis showed that the there was statistically significant difference in the time taken to reach full enteral feeds among the two groups. $(\mathrm{p}=.051)$

\section{DISCUSSION}

Many researchers have found a positive association with the use of probiotics and the time taken for reaching full enteral feeds. But unfortunately our study did not show any positive association between the two. The aim of the study was to prove a positive association with the usage of probiotics but it did not reveal any significant difference in the time taken to reach full enteral feeds.

\section{CONCLUSION}

Our study does have some limitations. The small sample size could be the reason. Since numerous researches show that there is a reduction in the time taken to reach full enteral feeds in preterm infants no standard guidelines are still established for the same. 